\title{
Pengaruh Sarana Dan Prasarana Pendukung Wisata Terhadap Kepuasan Wisatawan Di Umbul Ponggok, Klaten
}

\author{
Amin Kiswantoro ${ }^{1),}$ Dwiyono Rudi Susanto ${ }^{2)}$ \\ Sekolah Tinggi Pariwisata Ambarrukmo (STIPRAM) Yogyakarta \\ E-mail : aminkiswantoro@yahoo.co.id
}

\begin{abstract}
This study aims to examine the effect of innovation in infrastructure on visitor satisfaction at Ponggok Umbul tourist attraction, Klaten. The research method used is quantitative descriptive analysis method. The data collection technique is carried out through questionnaires using non probability sampling techniques to 100 respondents in Umbul Ponggok tourism object, with taking using incidental sampling techniques. The collected data is tabulated and then analyzed using simple linear regression analysis. From the results of calculations using SPSS 16, the results show that infrastructure facilities have an influence on the satisfaction of tourists visiting Umbul Ponggok with a value of $5.78 \%$, and $94.22 \%$ influenced by other variables not examined in this study. And from the results of the $T$ test it is known that the significance results are 0.016 or <from the probability value of 0.05 , this result shows that the innovation of infrastructure means has a significant effect on visitor satisfaction at the Ponggok Umbul attraction, Klaten.
\end{abstract}

Keywords: Tourist Satisfaction, Infrastructure Innovation, Umbul Ponggok

Abstrak-- Penelitian ini bertujuan untuk mengetahui pengaruh inovasi sarana dan prasarana terhadap kepuasan wisatawan di objek wisata Umbul Ponggok, Klaten. Metode penelitian yang digunakan adalah metode analisis deskriptif kuantitatif. Teknik pengumpulan data dilakukan melalui kuesioner menggunakan teknik non probability sampling untuk 100 responden di objek wisata Umbul Ponggok, dengan pengambilan menggunakan teknik sampling insidental. Data yang dikumpulkan ditabulasi dan kemudian dianalisis menggunakan analisis regresi linier sederhana. Dari hasil perhitungan menggunakan SPSS 16, hasil penelitian menunjukkan bahwa fasilitas sarana dan prasarana memiliki pengaruh terhadap kepuasan wisatawan yang berkunjung ke Umbul Ponggok dengan nilai 5,78\%, dan $94,22 \%$ dipengaruhi oleh variabel lain yang tidak diteliti dalam penelitian ini. Dan dari hasil uji T diketahui bahwa hasil signifikansi 0,016 atau < dari nilai probabilitas 0,05, hasil ini menunjukkan bahwa inovasi sarana dan prasarana memiliki pengaruh yang signifikan terhadap kepuasan pengunjung di objek wisata Umbul Ponggok, Klaten.

Kata kunci: Kepuasan Wisatawan, Inovasi Sarana dan Prasarana, Umbul Ponggok

\subsection{Latar Belakang}

Indonesia merupakan negara yang memiliki banyak potensi wisata yang tersebar di setiap daerah-daerah. Hal ini dikarenakan kekayaan alam yang melimpah dari Sabang sampai Merauke, sehingga menjadikan negara ini sebagai negara yang kaya akan wisata alamnya. Saat ini, baik pemerintah daerah maupun masyarakat mulai sadar akan pentingnya mengelola potensi wisata yang ada di sekitar tempat tinggal mereka. Seperti masyarakat di Desa Ponggok yang memiliki Umbul Ponggok sebagai salah satu destinasi wisata. Lebih tepatnya, umbul ponggok ini berada di Desa Ponggok, Kecamatan Pulanharjo, Kabupaten Klaten, Jawa Tengah.

Dulunya, Umbul Ponggok merupakan sumber mata air yang hanya difungsingkan sebagai irigasi untuk mengairi sawah dan perkebunan warga. Atas dasar inisiatif masyarakat setempat dengan dana mandiri, mereka merubah sumber daya alam ini menjadi salah satu objek wisata berupa pemandian atau wisata air yan dibuka untuk umum. Hingga akhirnya, Umbul Ponggok menjadi salah satu destinasi wisata unggulan di Kabupaten. Awalnya, Umbul Ponggok menawarkan wisata berbasis air, seperti pemandian air tawar pada umumnya. Namun, yang membedakan Umbul Ponggok dengan umbul yang lain adalah adanya ikan-ikan yang hidup di umbul tersebut, sehingga wisatawan dapat berenang bersama ikan-ikan tersebut. Ikan yang ada di Umbul Ponggok terdiri dari berbaga jenis dan ukuran, ada yang besar dan ada pula yang kecil dan mereka dapat hidup berdampingan dengan wisatawan yang berenang atau sekedar menikmati keindahan umbul tersebut. Kedalaman dari umbul ini beravriasi, antara 1 sampai 3 meter dan uniknya airnya tidak pernah keruh meskipun banyak wisatawan yang berenang di dalamnya.

Seiring berjalanya waktu, masyarakat sebagai pengelola selalu berinovasi untuk menarik minat wisatawan datang ke Umbul 
Ponggk, baik wisatawan domestik maupun manca negara. Hal ini dilakukan dengan melengkapi serta merenoavsi sarana prasarana atau fasilitas yang ada di Umbul Ponggok, seperti wahana permainan untuk anak-anak, kolam untuk anak-anak, peralatan menyelam, maupun fasilitas untuk berswafoto. Di Umbul Ponggok ini kita akan menemukan taman di dalam air, atau kendaraan di dalam air yang sengaja di sediakan oleh pengelola untuk media swafoto bagi wisatawan. Dari keunikan inilah angka kunjungan wisatawan selalu meningkat setiap tahunya, seperti dalam tabel berikut ini:

Tabel 1. Data Pengunjung Obyek Wisata

$$
\text { Umbul Ponggok }
$$

\begin{tabular}{|c|c|c|}
\hline No. & Tahun & Jumlah Pengunjung \\
\hline 1 & 2010 & 5.362 \\
\hline 2 & 2011 & 33.604 \\
\hline 3 & 2012 & 41.865 \\
\hline 4 & 2013 & 65.000 \\
\hline 5 & 2014 & 167.445 \\
\hline 6 & 2015 & 240.000 \\
\hline
\end{tabular}

Sumber: BUMDes Tirta Mandiri, 2016

Dilihat dari tabel di atas, angka kunjungan wisatawan selalu mengalami peningkatan setiap tahunnya. $\mathrm{Hal}$ ini menunjukkan banyak wisatawan yang tertarik untuk berkunjung ke Umbul Ponggok. Oleh karena itu, penulis termotivasi untuk melakukan penelitian yang berjudul "Pengaruh Sarana dan Prasarana Pendukung Wisata Terhadap Kepuasan Wisatawan Di Umbul Ponggok, Klaten"

\subsection{Kajian Pustaka}

\subsubsection{Difinisi Pariwisata}

Menurut Hermantoro (2011) membedakan pariwisata menurut objeknya menjadi 8 jenis yaitu :

1. Cultural tourism, adalah jenis pariwisata dimana motivasi orang-orang yang melakukan perjalanan karena adanya daya tarik dari senibudaya suatu daerah atau tempat tertentu. Jadi objek kunjungannya adalah warisan nenek moyang berupa benda-benda kuno atau situs-situs kuno yang memiliki nilai sejarah. Contoh: Candin Borobudur.

2. Natural tourism, adalah kegiatan pariwisata yang biasanya mempunyai daerah penyangga, contohnya : Gunung Ungaran dengan Gedong Songo-nya yang memiliki wisata Bandungan sebagai daerah wisata penyangga.

3. Technological tourism, adalah jenis pariwisata yang menyajikan teknologiteknologi yang ada namun langka atau tidak mudah mendapatkannya baik berupa teknologi modern maupun teknologi yang telah kuno. Misalnya: Museum Kereta Api Kuno di Ambarawa.

4. Historical tourism, adalah jenis pariwisata yang biasanya merupakan monumen atau tugu untuk mengingat suatu peristiwa heroik yang pernah terjadi di daerah tersebut. Contoh: Monumen Palagan Ambarawa, Monumen Pancasila Sakti di Lubang Buaya Jakarta.

5. Agrowisata, adalah perjalanan wisata yang dilakukan ke proyek- proyek pertanian, perikanan, ladang pembibitan dan sebagainya. Untuk jenis pariwisata ini, wisatawan dapat mengadakan kunjungan dan peninjauan untuk studi atau menikmati segarnya daerah pertanian, tanaman yang beraneka ragam jenis dan warnanya, proses pembibitan berbagai macam tanaman dan sebagainya. Misalnya: Agro Tlogo di Kabupaten Semarang.

6. Recuperational tourism, jenis pariwisata ini sama dengan pariwisata kesehatan. Tujuan orang-orang tersebut berwisata adalah untuk menyembuhkan penyakit. Contoh: Pemandian air panas di Ciater.

7. Religion tourism, perjalanan wisata yang dilakukan bertujuan untuk melihat atau menyaksikan dan mengikuti upacaraupacara keagamaan atau juga untuk mendatangi tempat-tempat tertentu yang dianggap memiliki nuansa agamis yang begitu kental. Contoh: Ziarah Walisongo.

8. Shopping tourism, adalah jenis pariwisata yang menonjolkan sisi penjualan produk tertentu khas dari wilayah tersebut. Misalnya: PKL (Pedagang Kaki Lima) di Jalan Malioboro Yogyakarta ataupun kerajinan perak di Kotagede Yogyakarta.

\subsubsection{Inovasi}

Inovasi dapat diartikan sebagai proses mengadopsi "sesuatu" yang baru oleh siapapun yang mengadopsinya, dan sebagai proses menciptakan produk baru. Sedangkan menurut Ellitan (2009) Konsep inovasi didefinisikan sebagai perubahan dalam organisasi yang didalamnya mencakup kreatifitas dalam menciptakan atau adaptasi produk baru jasa, ide, atau proses baru, baik yang sudah ada dalam organisasi maupun dikembangkan dari luar organisasi.

Menurut Suryani (2008), terdapat 2 konsep tentang produk baru sesuai dengan perspektifnya, yaitu:

1. Produk baru menurut perspektif perusahaan

Dalam perspektif perusahaan, sebuah produk dikatakan baru jika produk tersebut benar- benar baru menurut perusahaan. Baru bisa diartikan karena perusahaan belum pernah memproduksi sebelumnya, 
atau baru karena bahannya baru atau baru karena perusahaan menambahkan atributatribut yang berbeda dari produk yang pernah diproduksi sebelumnya.

2. Produk baru menurut perspektif produk Perspektif ini lebih menekankan pada atribut yang melekat pada produk itu sendiri dan pengaruhnya terhadap perilaku konsumen. Dalam perspektif ini, terdapat tiga jenis inovasi produk, yaitu:

1) Continuous Innovation

Tipe inovasi ini berupa penyempurnaan atau modifikasi dari produk yang telah ada. Perubahan yang dilakukan tidak secara mendasar (Radikal), sehingga tidak terdapat perubahan yang signifikan pada perilaku konsumen. Pada umumnya inovasi yang dilakukan perusahaan dapat berupa inovasi kemasan, tempat dan produk (perusahaan melakukan pengembangan produk baru, atas dasar produk yang sudah ada).

2) Dynamically Continuous Innovation Tipe Inovasi ini bersifat dinamis yang memungkinkan produk mengalami perubahan secara terus-menerus.

3) Discontinuous Innovation

Tipe inovasi ini menghasilkan perubahan dalam cara bagaimana manusia hidup, seperti penemuan pesawat terbang yang telah merubah perilaku dan gaya hidup manusia dalam berpergian.

\subsubsection{Sarana dan Prasarana Pariwisata}

Sarana pariwisata adalah segala sesuatu yang melengkapi dan atau memudahkan proses kegiatan pariwisata dapat berjalan dengan lancar. Menurut Yoeti (2012) sarana kepariwisataan dibagi menjadi tiga kelompok, diantaranya adalah sarana pokok (main tourism superstructure). Sarana pokok kepariwisataan adalah perusahaan yang hidup dan kehidupannya sangat tergantung kepada kedatangan orang yang melakukan perjalanan wisata, seperti travel agent, tour operator, angkutan wisata, rumah makan, akomodasi, objek wisata dan atraksi wisata.

Menurut Warpani (2007), prasarana pariwisata adalah segala sesuatu yang memungkinkan proses kegiatan pariwisata berjalan lancar. Prasarana tersedia untuk menunjang segala aktivitas wisata. Oleh karena itu, prasarana pariwisata sangat penting keberadaannya bagi sebuah destinasi wisata. Warpani (2007) mengelompokkan beberapa hal yang termasuk dalam prasarana, yaitu:

1. Aksesibilitas
Aksesibilitas merupakan faktor penting dalam proses berwisata, tingkat kemudahan untuk menjangkau suatu kawasan wisata dilihat dari aksesibilitas yang berupa kondisi jalan raya/ untuk mempersingkat waktu perjalanan.

2. Utilitas

Yang termasuk utilitas adalah, listrik, toilet, musholla.

3. Jaringan pelayanan

Yang termasuk jaringan pelayanan adalah, Pelayanan kesehatan dalam bentuk pos kesehatan atau kotak P3K. Keamanan, dalam bentuk pos keamanan, petugas keamanan, atau segala bentuk yang menjauhkan wisatawan dari tindakan kriminal selama berada di kawasan berwisata.

\subsubsection{Fasilitas}

Fasilitas adalah sumber daya alam maupun sumber daya buatan yang dimana dibutuhkan oleh wisatawan yang menjadi tujuan mereka berwisata. Serta kelengkapan tempat sebagai pendukung atau nilai tambah suatu obyek wisata untuk meningkatkan nilai kepuasan wisatawan yang datang ke obyek wisata. Untuk kesiapan obyek wisata yang akan di kunjungi oleh wisatawan di daerah tujuan wisata, prasarana wisata tersebut perlu dibangun dengan disesuaikan dengan lokasi dan kondisi obyek wisata yang bersangkutan. Pembangunan prasarana wisata yang mempertimbangkan kondisi dan lokasi akan meningkatkan aksesbilitas suatu obyek wisata yang pada gilirannya akan dapat meningkatkan daya tarik obyek wisata itu sendiri. Di samping berbagai kebutuhan yang telah disebutkan di atas, kebutuhan wisatawan yang lain juga perlu disediakan di daerah tujuan wisata, seperti bank, apotek, rumah sakit, pom bensin, pusat-pusat perbelanjaan dan lain-lain (Akrom, 2014). Komponen dalam fasilitas obyek wisata menurut Akrom (2014), Komponenkomponen yang termasuk ke dalam sarana dan prasarana yaitu :

1. Tangible Product (Produk yang nyata) terdiri dari : Prasarana wisata adalah semua fasilitas yang memungkinkan agar sarana kepariwisataan dapat hidup dan berkembang serta dapat memberikan pelayanan kepada wisatawan untuk dapat memenuhi kebutuhan selama dalam perjalanan. Misalnya jaringan jalan, sarana pelabuhan (udara, laut, darat), telekomunikasi, jaringan listrik, air bersih, rumah sakit dan lain sebagainya. Sarana produk kepariwisataan yaitu semua bentuk perusahaan yang dapat memberikan pelayanan kepada wisatawan. Misalnya : 
a. Di bidang usaha jasa pariwisata, seperti : biro perjalanan wisata, agen perjalanan wisata, pramuwisata, konvensi, perjalanan insentif dan pameran, konsultan pariwisata, informasi pariwisata.

b. Di bidang usaha sarana pariwisata, yang terdiri dari : akomodasi, rumah makan, bar, angkutan wisata dan sebagainya.

2. Intangible Product (produk yang tidak nyata) Pelayanan yang dimaksud dalam hal ini adalah sumber daya manusia yang bergelut dalam industri pariwisata dan pengetahuan teknik tentang pelayanan terhadap wisatawan. Dan sapta pesona yang terdiri dari 7K (keamanan, ketertiban, kebersihan, keindahan, kesejukan, keramah tamahan, kenangan) yang semuanya dilaksanakan secara total.

\subsubsection{Kepuasan Wisatawan}

Menurut Sunyoto (2013) kepuasan adalah tingkat perasaan seseorang setelah membandingkan (kinerja atau hasil) yang dirasakan dibandingkan dengan harapannya. Jadi, tingkat kepuasan adalah fungsi dari perbedaan antara kinerja yang dirasakan dengan harapan. Apabila kinerja sesuai atau bahkan melebihi dari yang diharapkan, maka pengunjung akan merasa senang atau puas. Sebaliknya apabila kinerja berada kurang dari yang diharapkan, maka pelanggan akan merasa kecewa atau tidak puas. Selain itu, pelanggan atau wisatawan bisa mengalami salah satu dari tiga tingkat kepuasan umum, yaitu :

1. Apabila kinerja di bawah harapan, pelanggan akan merasa kecewa.

2. Apabila sesuai dengan harapan pelanggan akan merasa puas.

3. Apabila kinerja bisa melebihi harapan maka pelanggan akan merasakan sangat puas, senang, atau gembira dengan hasil kinerja perusahaan tersebut.

Sedangkan menurut Maria (2002) menyebutkan bahwa terdapat tiga dimensi dalam mengukur kepuasan pelanggan secara universal, yaitu:

\section{Attributes related to product}

Dimensi kepuasaan yang berkaitan dengan atribut dari produk seperti penetapan nilai yang didapatkan dengan harga, kemampuan produk menentukan kepuasan, dan benefit dari produk tersebut.

2. Attributes related to service

Dimensi kepuasan yang berkaitan dengan atribut dari pelayanan misalnya garansi yang dijanjikan, proses pemenuhan pelayanan atau pengiriman, dan proses penyelesaian masalah.

3. Attributes related to purchase

Dimensi kepuasan yang berkaitan dengan atribut dari keputusan untuk membeli atau tidaknya dari produsen, seperti kemudahan mendapatkan informasi, kesopanan karyawan dan juga pengaruh reputasi perusahaan.

\subsection{Metode Penelitian}

Jenis penelitian ini merupakan penelitian deskriptif dan verifikatif. Melalui penelitian eskriptif ini dapat diperoleh gambaran variabel bebas (independent variable), yaitu inovasi produk yang memiliki 3 indikator yang terdiri dari Compatibility, Kompleksitas, Observability. Kemudian objek penelitian yang menjadi variabel terikat (dependent variable) adalah kepuasan pengunjung $(Y)$ yang memiliki tiga indikator yaitu attributes related to product (kualitas produk), attributes related to service (berkaitan dengan atribut dari pelayanan), attributes related to purchase (berkaitan dengan atribut dari keputusan untuk membeli atau tidaknya dari produsen).

\subsubsection{Teknik Pengumpulan Data}

Adapun teknik pengumpulan data yang digunakan peneliti dalam pengambilan data Primer dan sekunder, yaitu observasi, kuesioner, wawancara, dan penelitian kepustakaan untuk mencari data yang bersifat teori. Penghitungan dalam penelitian ini menggunakan alat bantu hitung statistika SPSS 16 for windows.

\subsubsection{Teknik analisa Data}

Dalam menganalisis data, model penelitian yang digunakan oleh penulis adalah deskriptif dan verifikatif dengan pendekatan kuantitatif. Teknik analisis deskriptif yaitu untuk variabel yangbersifat kuantitatif dan verifikatif untuk pengujian hipotesis dengan menggunakan statistika. Model persamaan Regresi Linear Sederhana yang digunakan adalah

Dimana:

$$
\mathbf{Y}=\mathbf{a}+\mathbf{b X}
$$

$Y=$ variabel dependent

$X=$ variabel Independent

$\mathrm{a}=$ konstanta

$\mathrm{b}=$ koefisien regresi

\subsection{Hasil dan Pembahasan}

\subsubsection{Gambaran Umum Obyek Penelitian}

Umbul Ponggok merupakan sebuah kolam alami yang di kembangkan menjadi wisata pemandian sekaligus snorkling yang cukup terkenal di Klaten. Umbul Ponggok 
sudah ada sejak zaman penjajahan Belanda, dengan ukuran $50 \times 25$ meter dan kedalaman rata-rata 1,5-2,6 meter. Tempat snorkling ini berbeda, karena airnya berasal dari sumber mata air yang segar dan jernih. Berbeda dengan kolam renang pada biasanya yang dasarnya berupa lantai keramik, dasar Umbul Ponggok masih alami berupa hamparan pasir, bebatuan dan ikan warna - warni sehingga suasananya benar - benar menyerupai bawah laut.

Meski dipenuhi ikan, air di Umbul Ponggok ini tidak amis sebab airnya mengalir terus. Selain sebagai tempat snorkling, Umbul Ponggok juga kerap dijadikan lokasi latihan diving bagi penyelam pemula. Umbul Ponggok juga dilengkapi dengan kolam khusus anakanak yang bias digunakan untuk berenang maupun bermain air. Umbul Ponggok pada tahun 2016 telah meraup keuntungan sebesar Rp 10,3 miliar, pada tahun 2017 hingga bulan Juli mendapat keuntungan sebesar Rp 8,5 miliar. Desa Ponggok saat ini menjadi desa yang pendapatannya paling tinggi di Kabupaten Klaten serta menjadi desa percontohan untuk desa - desa di Klaten maupun desa - desa di Indonesia.

Adanya penurunan pendapatan dari tahun 2016 ke tahun 2017 menunjukkan bahwa adanya penurunan kunjungan wisatawan. Oleh karena itu, mengelola berinisiatif untuk melakukan inovasi terhadap sarana dan prasarana yang ada di Umbul Ponggok. Berikut ini beberapa inovasi sarana dan prasarana yang akan ditambahkan di Umbul Ponggok untuk bias meningkatkan minat dan kunjungan wisatawan ke Umbul Ponggok:

Tabel 2. Sarana dan Prasarana di Umbul

\begin{tabular}{|c|c|c|}
\hline \multicolumn{3}{|c|}{ Ponggok } \\
\hline NO. & Sarana & Prasarana \\
\hline 1 & Kolam renang & Information Center \\
\hline 2 & Trampoline & Ticketing \\
\hline 4 & Kolam anak & $\begin{array}{l}\text { Hotel atau } \\
\text { penginapan }\end{array}$ \\
\hline 5 & $\begin{array}{l}\text { Berbagai jenis } \\
\text { dan ukuran } \\
\text { ikan }\end{array}$ & $\begin{array}{l}\text { Restoran atau } \\
\text { warung makan }\end{array}$ \\
\hline 6 & $\begin{array}{l}\text { Kendaraan } \\
\text { bermotor }\end{array}$ & Tempat parkir \\
\hline 7 & $\begin{array}{l}\text { Taman di } \\
\text { dalam air }\end{array}$ & Rest area \\
\hline 8 & $\begin{array}{l}\text { Alat diving and } \\
\text { walker }\end{array}$ & Event space \\
\hline 9 & Alat snorkling & Toilet \\
\hline 10 & $\begin{array}{l}\text { Wahana } \\
\text { permainan air }\end{array}$ & Mushola \\
\hline
\end{tabular}

Sumber: BUMDes Tirta Mandiri
Dari hasil penelitian yang dilakukan terhadap 100 sampel didapatkan hasil deskriptif karakteristik responden ke objek wisata Umbul Ponggok, didapatkan beberapa hasil, yaitu berdasarkan jenis kelamin menunjukan bahwa responden Umbul Ponggok yang berjenis kelamin laki- laki sebesar $52 \%$ atau sebanyak 52 orang dan perempuan sebesar $48 \%$ atau sebanyak 48 orang. Dengan usia pengunjung paling banyak adalah remaja dan dewasa atau $<35$ tahun, yaitu $64 \%$ atau sebanyak 64 orang.

\subsubsection{Analisis Deskriptif Variabel Inovasi}

1. Sarana Prasarana

Rekapitulasi hasil tanggapan pengunjung terhadap pelaksanaan inovasi sarana prasarana dapat dilihat dari tabel berikut:

Tabel 3. Rekapitulasi Hasil Tanggapan Wisatawan terhadap Inovasi Sarana Prasarana

\begin{tabular}{|l|l|c|c|c|c|}
\hline No & Sub variabel & $\begin{array}{c}\text { Item } \\
\text { pertanyaan }\end{array}$ & $\begin{array}{c}\text { Total } \\
\text { skor }\end{array}$ & $\begin{array}{c}\text { Rata- } \\
\text { rata }\end{array}$ & $\%$ \\
\hline 1 & Compatibility & 6 & 2.058 & 343 & 34,6 \\
\hline 2 & Kompleksitas & 2 & 713 & 356,5 & 35,9 \\
\hline 3 & Observability & 2 & 586 & 293 & 29,5 \\
\hline \multicolumn{2}{|l}{ Total } & 10 & 3.357 & 992.5 & 100 \\
\hline
\end{tabular}

Berdasarkan hasil rekapitulasi tanggapan atau respon wisatawan terhadap inovasi sarana prasarana di Objek Wisata Umbul Ponggok diperoleh nilai total skor sebesar 3.357 . Nilai total skor 3.357 termasuk dalam kategori "cukup tinggi". Hasil tersebut menunjukan bahwa tanggapan atau respon wisatawan terhadap inovasi sarana prasarana yang ada di Objek Wisata Umbul Ponggok dikatakan cukup baik, wisatawan cukup menyukai inovasi sarana prasarana yang dilakukan oleh pihak pengelola objek wisata Umbul Ponggok.

\subsubsection{Analisa Deskriptif Variabel Kepuasan Wisatawan}

Rekapitulasi hasil tanggapan rekapitulasi tanggapan atau respon wisatawan terhadap kepuasan wisatawan di Objek Wisata Umbul Ponggok dapat dilihat dalam tabel berikut:

Tabel 4 Rekapitulasi Hasil Tanggapan Pengunjung terhadap Kepuasan Wisatawan

\begin{tabular}{|c|c|c|c|c|c|}
\hline No & $\begin{array}{c}\text { Sub } \\
\text { variabel }\end{array}$ & $\begin{array}{c}\text { Jml item } \\
\text { pertanyaan }\end{array}$ & $\begin{array}{l}\text { Total } \\
\text { skor }\end{array}$ & $\begin{array}{l}\text { Rata- } \\
\text { rata }\end{array}$ & $\%$ \\
\hline 1 & $\begin{array}{l}\text { attributes } \\
\text { related to } \\
\text { product }\end{array}$ & 4 & 1526 & 381.5 & 34.9 \\
\hline 2 & $\begin{array}{l}\text { attributes } \\
\text { related to } \\
\text { servic }\end{array}$ & 4 & 1437 & 359.3 & 32.8 \\
\hline 3 & $\begin{array}{l}\text { attributes } \\
\text { related to } \\
\text { purchase }\end{array}$ & 3 & 1061 & 353.7 & 32,3 \\
\hline \multicolumn{2}{|r|}{ Total } & 11 & 4024 & 1.094 .5 & 100 \\
\hline
\end{tabular}

Berdasarkan rekapitulasi tanggapan atau respon wisatawan terhadap kepuasan 
wisatawan di Objek Wisata Umbul Ponggok diperoleh nila total skor sebesar 4.024. Nilai total 4024 termasuk dalam kategori "tinggi". Hasil tersebut menunjukan bahwa tanggapan atau respon wisatawan terhadap kepuasan wisatawan yang ada di Objek Wisata Umbul Ponggok dikatakan baik, wisatawan merasa puas melakukan kegiatan wisata di Umbul Ponggok.

\subsubsection{Uji Linearitas dan Regresi Linear} Sederhana

Berdasarkan hasil output uji linearitas, diperoleh nilai signifikasi yaitu sebesar 0,081 $>0,05$, yang artinya terdapat hubungan linear secara signifikan antara variabel inovasi sarana prasarana $(X)$ dengan kepuasan pengunjung ( $Y$ ). Dari hasil uji asumsi klasik yang telah dilakukan oleh peneliti, maka diperoleh hasil bahwa data sudah memenuhi persyaratan untuk dilakukannya analisis persamaan regresi linier sederhana. Dari hasil pengujian koefisien regresi linear sederhana diketahui bahwa variabel bebas inovasi sarana prasarana berpengaruh terhadap variabel kepuasan wisatawan sebesar 0,243.

Tabel 5 Hasil Uji Koefisien Regresi Linear Sederhana

\begin{tabular}{|c|c|c|c|c|c|c|c|}
\hline \multirow[b]{2}{*}{ Model } & \multicolumn{2}{|c|}{\begin{tabular}{|l} 
Unstandardized \\
Coefficients \\
\end{tabular}} & \multirow{2}{*}{\begin{tabular}{|l}
$\begin{array}{l}\text { Standardized } \\
\text { Coefficients }\end{array}$ \\
Beta
\end{tabular}} & & \multirow[b]{2}{*}{ Sig. } & \multicolumn{2}{|c|}{ Collinearity Statistics } \\
\hline & B & Std. Error & & $\mathrm{t}$ & & Tolerance & VIF \\
\hline 1 (Constant) & 32.934 & 3.333 & & 9.881 & .000 & & \\
\hline Inovasi Sarana Prasarana & .243 & .096 & .237 & 2.410 & .016 & 1.000 & 1.000 \\
\hline
\end{tabular}

\subsubsection{Hasil Uji T (Parsial)}

Dari hasil uji $T$, diperoleh nilai Sig sebesar 0,016 , sedangkan nilai probabilitas 0,05 . Artinya, nilai Sig kurang dari nilai probabilitas $(0,05>0,016)$. Dengan demikian, maka $\mathrm{H} 0$ ditolak dan $\mathrm{Ha}$ diterima, yang artinya $\mathrm{Ha}$ : Terdapat pengaruh positif inovasi sarana prasarana terhadap kepuasan pengunjung.

\subsection{Kesimpulan dan Saran}

Dari hasil penelitian dan analisis yang telah dilakukan oleh peneliti di objek wisata Umbul Ponggok, maka didapatkan kesimpulan sebagai berikut:

1. Tanggapan pengunjung terhadap variabel inovasi sarana prasarana mendapatkan total skor sebesar 3.357, dan termasuk dalam kategori "cukup tinggi". Hasil tersebut menunjukan bahwa tanggapan pengunjung terhadap inovasi sarana prasarana bisa dikatakan cukup baik, pengunjung cukup menyukai inovasi sarana prasarana yang dilakukan oleh pihak objek wisata Umbul Ponggok.

2. Tanggapan pengunjung terhadap variabel kepuasan

pengunjung mendapatkan total skor sebesar 4.024 dan termasuk pada kategori "tinggi". Hasil tersebut menunjukan bahwa tanggapan pengunjung terhadap kepuasan pengunjung bisa dikatakan baik, pengunjung merasa puas melakukan kegiatan wisata di Umbul Ponggok.

3. Penelitian ini menunjukan bahwa inovasi sarana prasarana berpengaruh positif dan signifikan terhadap kepuasan pengunjung, dimana hasil koefisien regresi untuk pengaruh inovasi sarana prasarana (X) terhadap kepuasan konsumen (Y) memiliki koefisien regresi positif sebesar 0,243 dengan nilai signifikasi sebesar 0,016 atau lebih kecil dari nilai probabilitas yaitu sebesar 0,05. Dengan demikian diketahui bahwa inovasi sarana prasarana berpengaruh pada kepuasan konsumen sebesar 0,243 yang berarti juga semakin tinggi inovasi sarana prasarana maka semakin tinggi kepuasan pengunjung. Sehingga hipotesis kedua bahwa terdapat pengaruh inovasi sarana prasarana terhadap kepuasan pengunjung ( $\mathrm{Ha})$ diterima.

Saran yang direkomendasikan peneliti dalam memberikan alternatif penyelesaian masalah ini antara lain:

1. Adanya inovasi sarana dan prasarana di obyek wisata Umbul Ponggok, perlu dilakukan perencanaan yang matang, agar hasilnya lebih maksimal. Apabila perencanaan dilakukan dengan ketidak hati-hatian akan menimbulkan kesan yang kurang nyaman bagi pengunjung, yaitu dikarenakan lahan yang tidak begitu luas, sehingga dapat menimbulkan kesan terlalu penuh atau sesak di obyek wisata Umbul Ponggok.

2. Peningkatan partisipasi seluruh stakeholders termasuk pemerintah dalam mengembangkan obyek wisata Umbul Ponggok.

3. Bagi penelitian selanjutnya, dapat dilakukan pengembangan dengan menambahkan variabel-variabel lain yang belum diteliti dalam penelitian ini.

4. Hasil penelitian ini dapat dijadikan sebagai referensi bagi penelitian selanjutnya untuk pengembangan objek wisata Umbul Ponggok.

\section{Daftar Pustaka}

[1] Ellitan, Lena\&Anatan. (2009). MANAJEMEN INOVASI : Transformasi Menuju Organisasi Kelas Dunia. Bandung : Alfabeta.

[2] Maria, Sylvia et.al. (2002). Hubungan Citra toko dengan kepuasan konsumen 
pada pasar swalayan BP Surabaya. Unitas Vol 11 No. 1

[3] Ratnasari, Ririn \& Aksa, Mastuti. (2011). Manajemen Pemasaran. Bogor:Jasa Ghalia Indonesia.

[4] Suchaina. (2014). Pengaruh Kualitas Fasilitas Sarana Dan Prasarana Terhadap Peningkatan Jumlah Pengunjung Wisata Danau Ranu Grati. STKIP PGRI pasuruan.

[5] Sukarmen et.al. (2013). Analisis pengaruh Inovasi Produk Terhadap Kepuasan Konsumen dengan Keunggulan Bersaing Sebagai Variabel Intervening Pada Produk Gula Pasir Sebelas (GUPALAS)
Pabrik Gula Semboro PTPN XI (PERSERO). JEAM vol XII No. 1/2013.

[6] Sunyoto, Danang. (2013). Teori, Kuesioner, \&Analisis Data. Yogjakarta: Graha IImu Suryani, Tati.(2008). Perilaku Konsumen. Jogyakarta: Graha IImu.

[7] Veri et.al. Pengaruh Diferensiasi, Variasi, dan Inovasi Terhadap Kepuasan Konsumen Melalui Keunggulan Bersaing Pada Produk Edamame PT. Mitratani 27 Jember. UNEJ. E-journal Ekonomi dan Akutansi.

[8] Yoeti, A. Yoeka. (2012) .Pengantar Ilmu Pariwisata. Bandung: Angkasa. 